\title{
Topic Study Group No. 35: Role of Ethnomathematics in Mathematics Education
}

\author{
Milton Rosa, Lawrence Shirley, Maria Elena Gavarrete \\ and Wilfredo V. Alangui
}

\section{Introduction}

Participants of TSG35 addressed numerous themes related to ethnomathematics and its pedagogical action. In order for us to better understand the development of ethnomathematics, members discussed both current and future perspectives of this program. As well, its goals, objectives, and assumptions were analyzed in regards to the encouragement of an ethics of respect, solidarity, and cooperation across cultures. These topics were connected by themes of culturally relevant pedagogy, innovative approaches in ethnomathematics, and the role of this program in mathematics education.

In the ethnomathematics topic study group at ICME-13, there were 28 accepted papers written by 36 researchers from 19 countries: Australia, Belgium, Brasil, China, Costa Rica, Greece, India, Israel, Italy, Mozambique, Nepal, New Zealand, Peru, Philippines, Portugal, South Africa, Spain, Tanzania, and United States of America. From these papers, 24 were presented. Approximately, 30 researchers participated in the discussions conducted in each one of the 11 sessions ( 7 regular sessions and 4 oral communication sessions available in the congress). The majority of the papers presented in the ethnomathematics study group were by researchers from Brazil (7) and Nepal (3).

Co-Chairs: Milton Rosa, Lawrence Shirley.

Team members: Wilfredo V. Alangui, Maria Elena Gavarrete.

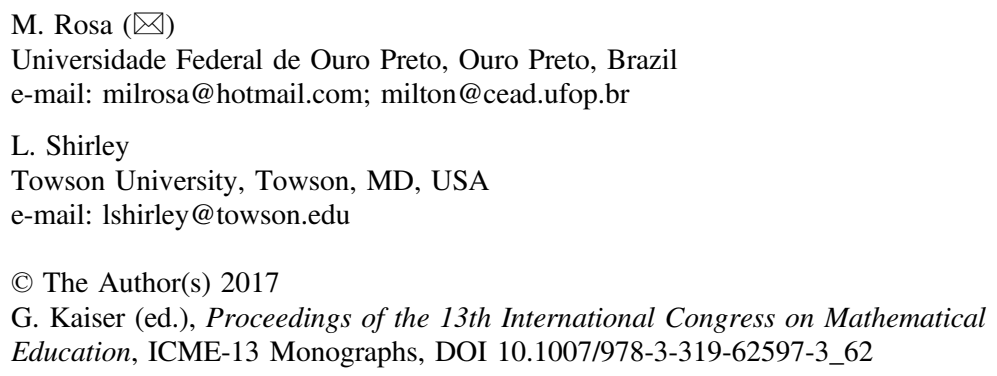




\section{Description of the Activities}

Ethnomathematics grew out of the history of mathematics, mathematics education, and issues of mathematics in anthropology, sociology, economic, environmental concerns, and political science. It recognizes that the members of cultural groups develop activities that involve mathematical thinking. In order to allow the ethnomathematics community to discuss important issues related to this program, 7 regular sessions of the TSG35 were developed.

(a) July 26th, 2016

Opening Session: Pedagogical Action of the Ethnomathematics Program

Ubiratan D'Ambrosio and Milton Rosa (Brazil)

Ethnomathematics and its pedagogical action

(b) July 27th, 2016

\section{Two Parallel Sessions}

Marcos Cherinda (Mozambique)

From defrosting hidden mathematical knowledge to its formal learning: reviewing Gerde's research approach

Wilfredo Alangui (Philippines)

There is a theory behind what we're doing! Ethnomathematics and indigenous peoples' education in the Philippines

Morane Almeida Oliveira (Brazil)

Proposal for a methodological approach for the technical course for indigenous agroforestry agents in the state of Acre

Tony Trinick; Uenuku Fairhall; Tamsin Meaney (New Zealand)

Cultural and Mathematical Symmetry in Maori meeting houses

Veronica Albanese; Natividad Adamuz-Povedano; Rafael Bracho-López (Spain)

Ethnomathematics: two theoretical views and two approaches to education

Charoula Stathopoulou (Greece)

Once upon a time ... the Gypsy boy turned 15 while still in the first grade

(c) July 29th, 2016

Symposia: Innovative Approaches in Ethnomathematics

Daniel Clark Orey (Brazil)

The Critical-reflective Dimension of Ethnomodeling

\section{Parallel Session}

Miriam Amit; Fouse Abu-Qouder (Israel)

Weaving culture and mathematics in the classroom: the case of Bedouin ethnomathematics

Karen François (Belgium)

Wittgenstein's late philosophy as a philosophical foundation for ethnomathematics

Mogege Mosimege (South Africa) 
The role of language in ethnomathematical research and implications for mathematical teaching and learning

(d) July 30th, 2016

\section{Two parallel sessions}

Jaya Bishnu Pradhan (Nepal)

Chundaras' culture and mathematical ideas

Maria Cecília Fantinato; José Ricardo Souza Mafra (Brazil)

Aritapera's craftswomen: informal learning processes in an ethnographic study in ethnomathematics

Tod Shockey; John Bear Mitchel (United States of America)

An ethnomodel of a Penobscot lodge

There were also 4 oral communication sessions attached to the ethnomathematics topic study group with 10 presenters from Australia, Brazil, India, Italy, Nepal, Peru, and Tanzania.

\section{(e) July 26th and 27th, 2016}

\section{Four Parallel Sessions}

\section{Hongshick Jang (Tanzania)}

Language, ethnomathematics and technology in mathematics education challenges and pitfalls: the case of Tanzania.

Toyanath Sharma (Nepal)

Meaningful mathematics through cultural artifacts.

Alexandrina Monteiro; Jackeline R. Mendes (Brazil)

Knowledge mobilization in cultural practices: ethnomathematics as a counter-conduct movement.

Kay Owens (Australia)

The role of culture and ecology in visuospatial reasoning: the power of ethnomathematics.

Franco Favilli; Fiorenza Turiano (Italy)

On which finger will the number fall?

José Ricardo Mafra; Maria Cecilia Fantinato (Brazil)

Perceived techniques and processes of craftswomen in Santarém/PA.

María del Carmen Bonilla (Peru)

Tools of history of mathematics and dynamic geometry in the pre-service training in intercultural bilingual education.

Ramesh Neupane (Nepal)

Teaching and learning mathematics in a cultural context: ping as a project.

Sudhakar Agarkar (India)

Understanding the units of length measurement used by tribal people in India.

André Gerstberger; Ieda Maria Giongo (Brazil)

Ethnomathematics look at mobile usage regarding teaching mathematics processes in elementary education final years.

The presentations focused on and discussed ethnomathematics as a line of study and research of mathematics education from the many diverse perspectives and 
points of view brought to the group from all over the world. Together, presenters are investigating the roots of mathematical ideas and practices, starting from the way individuals see and use mathematical thinking in different cultural groups. In other words, ethnomathematics studies seek to identify mathematical practices that begin with the knowledge of the others in their own terms and rationality.

Because ethnomathematics studies the cultural roots of mathematical knowledge beginning with the various ways in which different cultural groups mathematize including academic mathematics, our study of ethnomathematics considers the historical evolution of mathematical knowledge with the acknowledgment of all social and cultural factors that form this ongoing and dynamic development.

\section{Discussions and Reflections}

The various presentations recognized how members of distinct cultural groups develop unique techniques, methods, and explanations that allow them alternative understandings, comprehensions, new actions, and a transformation of societal norms. Such historical research field has been a foundational area in ethnomathematics and continues to build a database of examples of mathematical thinking in distinct cultural groups.

It is evident from the discussion from TSG35 that the theoretical basis of an ethnomathematics program offers a valid alternative to traditional studies of history, philosophy, cognition, and pedagogical aspects of mathematics. Therefore, there is a growing sensitivity to the understanding and comprehension of mathematical ideas, procedures, and practices developed by the members of distinct cultural groups. This is due primarily to the expansion of studies related to culture, history, anthropology, linguistics and ethnomathematics.

Because ethnomathematics offers a broader view of mathematics, including its ideas, notions, procedures, processes, methods, and practices rooted in distinct and diverse cultural environments, this aspect leads to increased evidence of cognitive processes, learning capabilities, and attitudes that influence the learning processes occurring in classrooms. In addition to reflecting on social and political dimensions of ethnomathematics, another important aspect of this program is the possibility for the development of innovative approaches for a dynamic and glocalized society as outlined by D'Ambrosio.

The results of our discussions within the TSG35 show that it is important to understand the diverse sociocultural representations and concepts of ethno developed from distinct ideas, procedures, practices, and dimensions of space and time through the relationships between members of cultural groups. This aspect shows that, currently, a more sensitive understanding of diverse mathematical ideas, procedures, and practices developed by members of diverse cultural groups has become increasingly available through the growth of the fields of ethnology, culture, history, anthropology, linguistics, and ethnomathematics. 
The insights gleaned from the presentations and from our discussions demonstrated the breadth and depth of how ethnomathematics influences the teaching and learning of mathematics, how it broadens our understanding of the nature of mathematical knowledge, and how it helps to create a just and inclusive society. Our discussions at the TSG 35 shows that it is necessary to pursue the current agenda of the ethnomathematics program in order to continue its progressive trajectory that contributes to the achievement of social justice and peace with dignity for all.

\section{Final Considerations}

From the presentations and discussions conducted during the regular and oral communication sessions of TSG35, it is possible to identify three unique characteristics that are interrelated.

1. It is necessary to continue to support and encourage further investigations in regards to innovative approaches in ethnomathematics programs especially in relation to social justice, civil rights, indigenous education, professional contexts, the playing of games, urban and rural contexts, and ethnomodelling.

2. An important change in mathematical instruction needs to accommodate continuous and ongoing changes in the demographics of students in mathematics classrooms around the world. Since it proposes that educators contextualize their mathematics teaching/learning by relating mathematical content to the sociocultural experiences of their students, it has become necessary to integrate culturally relevant pedagogies and diverse ethnomathematics perspectives into existing teacher education programs. Ethnomathematics intends to make school mathematics relevant to students through a more culturally relevant view of mathematics.

3. It is important to look at the diverse circumstances leading to the formulation of social, historical, cultural, political, and educational imperatives, and to realize that these are linked to one of the main goals of ethnomathematics, which is to broaden our conception of the diverse nature of mathematics. This includes specific examples of mathematical applications and models from an increasing number of diverse cultural groups.

From the discussions provided in this topic study group it is possible to conclude that mathematical knowledge is constructed by developing ideas, procedures, and practices that are common to the members of distinct cultural groups. This mathematical knowledge enables these members to elaborate and use their abilities that include the universal processes of counting, locating, measuring, drawing, representing, playing, understanding, comprehending, explaining, and modeling to solve problems they face daily.

Ethnomathematics provides mathematics educators an important framework to enable the transformation of mathematics so that it can better contribute in realizing the dream of a just and humane society. In this regard, mathematics is considered a 
powerful tool to help people build a civilization with dignity for all, in which inequity, arrogance, violence, and bigotry have no place, and in which threatening life, in any form, is rejected.

Presenters in this group shared the necessity for further discussions of issues related to mathematics education, classroom practices, and valuing the mathematical knowledge developed in specific cultural groups, and which helps to clarify the nature of mathematical knowledge.

Open Access Except where otherwise noted, this chapter is licensed under a Creative Commons Attribution 4.0 International License. To view a copy of this license, visit http://creativecommons. org/licenses/by/4.0/.

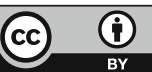

